\title{
Mechanical Properties of Polypropylene (PP) - Montmorillonite (MMT) Nanocomposites for Pre-Fabricated Vertical Drain (PVD) Application
}

\author{
N.A.Selamat ${ }^{1}$, M.N.M.Ansari ${ }^{2 *}$, Zainudin Yahya $^{3}$, Ragunatha E.Naicker $^{4}$ \\ ${ }^{1}$ Institute of Power Engineering, \\ ${ }^{2}$ Department of Mechanical Engineering, \\ Universiti Tenaga Nasional, Kajang 43000 Malaysia. \\ ${ }^{3}$ Capital Envoy (M) Sdn. Bhd., Selangor, Malaysia. \\ Corresponding author E-mail: ansari@ uniten.edu.my
}

\begin{abstract}
Polypropylene (PP) - montmorillonite (MMT) blends were prepared by melt-mixing method followed by injection molding method. The optimum process melt-temperature was set at $195^{\circ} \mathrm{C}$, the injection speed of $15 \mathrm{cc} / \mathrm{s}$, injection pressure of $30 \mathrm{MPa}$ and cooling time of 20 sec. was used for the sample preparation. Investigation shows, addition of MMT nanoparticles have improved the mechanical properties. The tensile test and impact test were conducted at room temperature and atmospheric pressure. The tensile modulus and yield strength improved with increasing MMT content, however, elongation at break was reduced as the MMT content was increased from $2 \mathrm{wt} \%$ to $8 \mathrm{wt} \%$. The Izod impact strength is also affected by the addition of MMT content. Nanocomposites based on PP containing $8 \mathrm{wt} \%$ of MMT showed higher impact strength than the other compositions and Neat PP (control). The influence of MMT content on impact strength increased with MMT content which is a significant result required for pre-fabricated vertical drain (PVD). Further investigations are required to study the mechanical properties of the PVD using PP - MMT nanocomposites to replace the existing material (PP).
\end{abstract}

Keywords: Montmorillonite (MMT); mechanical properties; nanocomposite; Polypropylene (PP); pre-fabricated vertical drain (PVD).

\section{Introduction}

Several studies have shown that the usage of geosynthetic reinforcement naturally also diminishes the construction expenses, improve the feasibility of construction, and the stability of embankments on deficient foundation soils. Prefabricated vertical drain (PVD) has been used extensively for the enhancement of soft soil by surcharge preloading [1] and successfully in design project across the world. . PVDs has been successfully applied as an effective method of improving soil in many coastal regions such as Tianjin Port, China, Changi Airport, Singapore and Second Bangkok International Airport, Thailand [2]. It is widely applied in civil, geotechnical engineering application such as roads, airfields, railroads, embankments and retaining structures in Malaysia also.

PVDs are installed to quicken the consolidation settlement process encouraged by the pre-loading of typically consolidated lowpermeability soil. By acquaint with the vertical drains the drainage path are reduced and, therefore the time consumed for excess water pore water pressure, stimulate by the loading operation, to dispelled will be reduced [3]. The strength gain in the foundation during embankment involving the PVDs was verify the achievement in design [4].

PVDs are also known as Wick Drains are fabricated drain strips be formed of a polypropylene core wrapped in non-woven filter, ultrasonically welded at the edges (see Figure 1). As discussed, the effectiveness of PVD in soil enhancement is pretentious by the quality of the PVD itself [5].The one of factors in soil improve- ment use are sufficient tensile strength and discharge capacity need to certify.Frequently, in large-scale soil improvement project ,million meters of PVDs will be used.Therefore, the unit cost become a major deliberation. One of the method to enhance the cost-effectiveness of PVD is to improve the quality of PVD especially no increase in material costs [6].

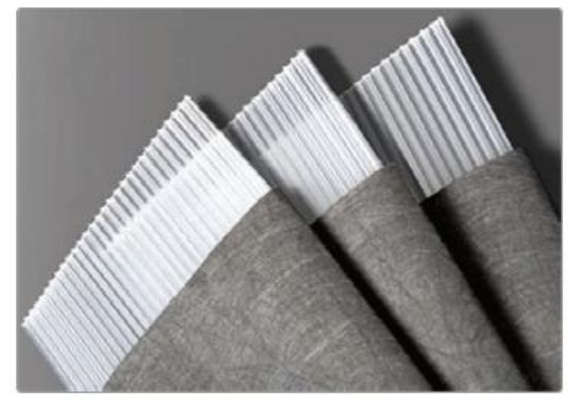

Fig. 1: PVD manufactured by Capital Envoy (M) Sdn.Bhd.(CeTau)

PVDs are mostly made of polypropylene and are relatively inexpensive, offer high water conductivity and can be set up at close spacing, thus shortening the path of the pore water in the impermeable soil and accelerate the consolidation process. By utilizing PVD, disturbance to substrata is limited, highspeed and high depth installation can be achieved and as well as close spacing is applicable [7]. However, high usage of polymeric materials throughout the manufacturing of traditional synthetic PVDs has been charged 
for their bad carbon footprint [8]. Besides, as the consolidates, reducing the thickness of the clay layer, the drain undergoes bending and kinking distortion as well as clogging. The kinking behavior of drain is depended on the elasticity of the drain and modulus of the nearby clay. A more flexible drain core will result in to larger reduction in discharge capacity. Furthermore, sharp kinks will decrease flow through the drain greater than gradual bends [2],[9].

An even diffusion of nanoparticles into the polymer matrix primes to a significant enhancement in the impressive properties of nanocomposites as equated to those of the conventional composites strengthened with micro-particles [10-11]. Nanoparticle aggregation distresses and reduces the polymer nanocomposite creep resistance [12]. The surface-to-volume ratio of the nanoparticles would be notably greater than that of micro-particles. It can improve the interfacial reactivity between the silica nanoparticles and polymer matrix. This resulting of the nanoparticle/polymer interaction is the creation of interphase region [13-14].

Nowadays, natural filler an alternate method has arose relating the use of natural fillers as one of the most interesting material that can be make use of to improve the properties of the final nanocomposite. Between the nanofillers used in nanocomposites, clays certainly play a key role as different types of clay reinforcement are currently conquered the polymer trades because they have verified good performances [15-20].

However, the combination of clay typically results in a deterioration of the tensile properties like tensile extension at break and impact strength. Several researchers defined polymer-clay nanocomposites based on single polymer matrix. A new technique in the nanocomposites research include in nanocomposites based on blends of two or more polymeric materials. Hence, some studies interrelated to nanocomposites of the blends have been reported, especially for polypropylene/polyamide-6/clay (PP/PA-6/clay) blends [21-24].

The topic in polymer/clay nanocomposites however, did not commercialize from the academic rings but from Toyota Company by using nylon/clay nanocomposites in their cars in 1989. Modest accumulation of clay providing substantial surges in tensile strength, tensile modulus and storage modulus with almost no reduction in impact resistance [22], [25].

Polymer/clay composites based on layered silicates are generally classified into three types depending on the extent of separation of silicate layers and interspersing of polymer chains. These are conventional composites, intercalated nanocomposites and exfoliated nanocomposites. If the clay layers are totally separated from each other to generate a disordered array with polymer chains entering galleries, the composite is mentioned to be exfoliated. The range of dispersion of clay in polymer matrix hang on the properties of polymer and clay, relations between polymer, clay, and modifying agents, processing conditions[22],[25]. Montmorillonite, an associate of the smectite group and having a 2:1 of clay, combination of mineral. It is naturally swelling characteristic and consolidation as well [26-27], It is also used in the structural [28] and to prevent the leakage of fluids. Recently, numerous groups have exposed that clays can efficiently reduce the domain size of polymer blends and they can play a role as compatibilizer in numerous immiscible polymer blends [22-24].

The PP/hydroxyapatite (HA) composite was manufactured using a procedure alike to that used for PP-MMT[29]. Manoraj et al. studied the influence of processing conditions on the mechanical behavior of the PP-HA composite with injection molding, and found that injection molding process because of the intensive mixing and shearing of the polymer [29-30].

Thus, this project aims to design an environmental friendly and more rigid material to prevent bending and ensure effective discharge capacity by incorporating PP nanocomposites containing montmorillonite (MMT). In this work, the MMT nanoparticles were used to prepare the PP composites with different MMT concentration. The impact of different MMT concentration on the mechanical properties such as Tensile strength, Young's modu- lus, \% elongation, and Izod impact strength was investigated. For this study, blends containing PP and MMT were prepared by using the direct melt blending in a twin-screw extruder come after by injection molding. This study aims at an experimental evaluation of the mechanical properties of nanocomposites which can be used for PVD applications.

\section{Experimental}

\subsection{Material}

A commercial polypropylene impact copolymer (TITANPRO SM 840 ) with melt flow index (MFI) of $0.7 \mathrm{~g} / 10 \mathrm{~min}$ at $2.16 \mathrm{~kg}$ and $230{ }^{\circ} \mathrm{C}$ was supplied by M/s.Capital Envoy Sdn.Bhd. Malaysia. Montmorillonite (MMT) was purchased from Sigma-Aldrich (Merk), Gemany. It has a $\mathrm{pH}$ of 3-4 and the average surface area of $250 \mathrm{~m}^{2} / \mathrm{g}$.

\subsection{Sample Preparation}

The nanocomposites were set using an intermeshing co-rotating twin screw extruder (Nanjing Norda Xinye Extrusion Equipment Co., Ltd: TDS-16) with a screw speed of $40 \sim 60 \mathrm{rpm}$ and barrel temperature $170-195^{\circ} \mathrm{C}$. The MMT content, exclusive of the organoclay without any surfactant, was varied from 2 to 8 wt\%.(see Table 1). For comparison basis neat PP was also subjected to processing under the same circumstances. All components were dosed together in a single gravimetric feeder. The feeder speed was synchronized with the screw speed. Extruded wire was cut using an automated cutter and nanocomposite granules were collected dried at $70^{\circ} \mathrm{C}$ for $4 \mathrm{~h}$ in a hot air oven and then injection molded into standard tensile bars as per the American Standard Test Method (ASTM D-638, Type II) and Izod test specimen (ASTM D-256) using Haitan HM60 injection molding machine with a barrel temperature range of $170-190^{\circ} \mathrm{C}$, die temperature of $200^{\circ} \mathrm{C}$ and a mold temperature of $40^{\circ} \mathrm{C}$. The injection and holding pressures were maintained at $30 \mathrm{MPa}$. The optimal process settings were taken from the previous study on optimizing process parameters for PP materials [29]. Five replicates were used in both tensile and impact tests.

Table 1: The formulation of PP-MMT nanocomposite

\begin{tabular}{|c|c|c|c|}
\hline S.No. & Sample ID. & PP $(\mathrm{wt} \%)$ & MMT(wt\%) \\
\hline 1 & Neat PP & 100 & 0 \\
\hline 2 & PPMMT2 & 98.0 & 2.0 \\
\hline 3 & PPMMT4 & 96.0 & 4.0 \\
\hline 4 & PPMMT6 & 94.0 & 6.0 \\
\hline 5 & PPMMT8 & 92.0 & 8.0 \\
\hline
\end{tabular}

\subsection{Measurement}

Tensile test was conducted on a Zwick/Roel Z100 universal testing machine. Strain rate was set at $5 \mathrm{~mm} / \mathrm{min}$. The tensile test specimen as per the ASTM D-638 standard dimension is shown in Figure 2.

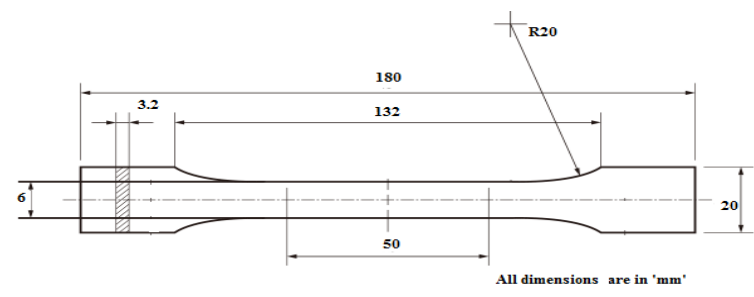

Fig. 2: Tensile test specimen dimensions (ASTM D-638):

Izod impact tests were completed at room temperature on notched specimens cut at the center of the injection molded Izod bars using a Zwick/Roel impact test model HIT 50P (see Figure 3). 


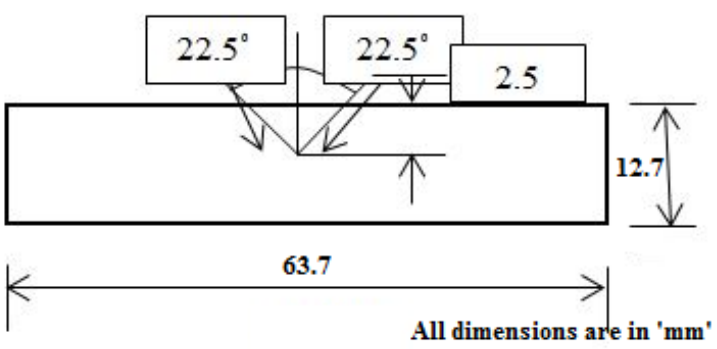

Fig. 3: Izod impact test specimen dimensions (ASTM D-256)

\section{Results and Discussion}

This work emphasize the importance of nanoclay and its reinforcement state in the nanocomposites containing PP. Nanoclay as well as clay localization at the interface of thermoplastic such as PP are investigated. Mechanical properties of a series of nanocomposites containing PP and MMT were compared and discussed with differ concentration of MMT nanoclay. PP-MMT nanocomposite samples were prepared using melt-mixing and injection moulding method as described in the previous section. The mechanical properties, especially the tensile properties and impact strength of the PP-MMT composites are discussed. It is known that PP molecules have solid interaction with the MMT surfaces, which should encourage the diffusion of the PP molecules into the MMT galleries.

\subsection{Tensile Properties}

The tensile properties of injection molding specimens without and with MMT are shown in Table 2. Tabulated results shows the reinforcement effect of MMT on the the yield strength, tensile modulus and strain at break of PP-MMT nanocomposites.

Table 2: Mechanical properties of PP-MMT nanocomposites

\begin{tabular}{|c|c|c|c|c|}
\hline S.No. & Sample Id & $\begin{array}{c}\text { Yield stress } \\
(\mathrm{MPa})\end{array}$ & $\begin{array}{c}\text { Tensile } \\
\text { modulus }(\mathrm{MPa})\end{array}$ & $\begin{array}{c}\text { Strain at } \\
\text { break } \\
(\%)\end{array}$ \\
\hline 1 & Neat PP & $23.01 \pm 0.1$ & $826.95 \pm 0.2$ & 120.9 \\
\hline 2 & PPMMT2 & $24.95 \pm 0.3$ & $880.88 \pm 0.4$ & 112.8 \\
\hline 3 & PPMMT4 & $26.72 \pm 0.4$ & $891.08 \pm 0.5$ & 91.9 \\
\hline 4 & PPMMT6 & $27.27 \pm 0.5$ & $912.19 \pm 0.3$ & 72.2 \\
\hline 5 & PPMMT8 & $28.60 \pm 0.3$ & $920.42 \pm 0.5$ & 55.0 \\
\hline
\end{tabular}

\subsubsection{Yield Strength}

An enhancement in the yield stress was observed in the PP-MMT when compared with Neat PP. The upsurge in yield strength of PP-MMT $8 \mathrm{wt} \%$ was of $24.3 \%$ and is maximum compared to other loading level of MMT respectively. It is observed that the increase in yield strength is linearly proportional with the MMT content. The MMT acted as reinforcing member as assumed, resulting in finer grain size with the improvement in the tensile properties. The improvement in the both tensile modulus and tensile strength may be presumably due to stress transfer between the matrix and the clay layers. For single nano-sized MMT fillings, a little improvement on yield strength were achieved in comparison with those of neat PP. Further investigation is under study to characterize the microstructure and morphology of the fractured surface of the nanocomposites.

\subsubsection{Tensile Modulus}

From Table2, The modulus increases as MMT \% loading increases from $2 \mathrm{wt} \%$ to $8 \mathrm{wt} \%$. The increase in tensile modulus of PP-MMT $8 \mathrm{wt} \%$ was of $11.25 \%$ and is maximum compared to other loading level of MMT respectively. The effect of MMT on the PP matrix has a better tensile modulus and hence stiffness is improvd. This result is contrary to the research findings by Calcogno et al. [22], with a concurrent decrease of Young's modulus, yield stress, and elongation at break by clay addition in the uncompatibilized blend of two different polymers such as PP and polyethylene terephthalate (PET). This could be due to the immiscility of the both polymers viz. PP and PET which has a poor bonding. The MMT particles were unable to compatibilize the both polymers. Parallel improvements had been ascertained for the PP/PET/PP-MA/clay [22]. This nanocomposite also showed the higher tensile modulus, about $785 \mathrm{MPa}$, and no significant difference in tensile strength is observed for all systems studied [22].

\subsubsection{Strain at Break}

A decrease of the strain at break in percentage was observed when MMT content was increased from $2 \mathrm{wt} \%$ to $8 \mathrm{wt} \%$ when compared to the Neat PP. The \% elongation (strain) at break has reduced from $120 \%$ to $55 \%$ by the addition $8 \mathrm{wt} \%$ of MMT (refer to Table 2 ). The result trend with other research studies reported [22]. The PP phase in the nano-sized pores outspreading along the channels to the openings, which could improve the interaction through the entanglement and inter-diffusion between the matrix and the particulate on the other hand. This could be a valid reason for the reduction of the elongation as the nano MMT content is increased.

\subsection{Impact Strength}

The ASTM D256 - 02 standard has been controlled for the Izod impact strength evaluation. Average values of the impact strength of PP-MMT nanocomposite are shown in Figure 4.

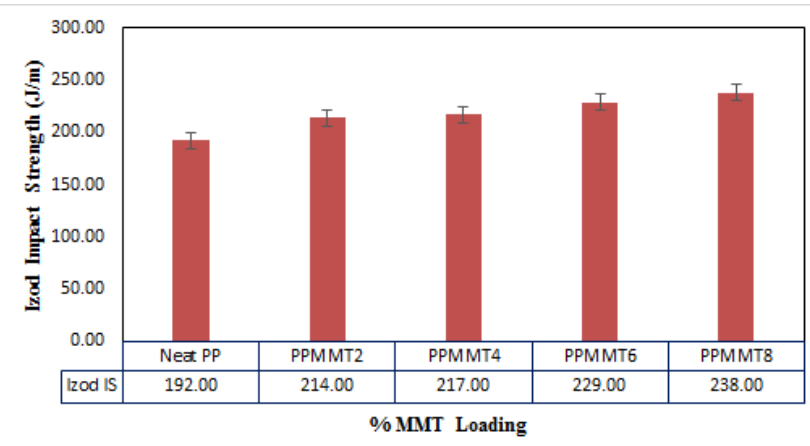

Fig. 4: Izod impact strength of PP-MMT nanocomposite

A graph was plotted based on these values to discover the pattern of the impact strength which is presented in Figure 4 that shows the 5 different samples taken from various compositions and then averaged to obtain a precise reading of the impact strength. The neat PP has the lowest impact strength of $192.00 \mathrm{~J} / \mathrm{m}$ and the most highest among all the samples are PPMMT8 (8wt\% MMT) has recorded $238.00 \mathrm{~J} / \mathrm{m}$. Impact fractures are generally due to reduced interfacial bonding persuaded by micro-spaces between the filler and polymer matrix, and these caused several micro-cracks when impact occurred, which induced crack propagation easily. Increase in the impact strength of the PP-MMT composites could be due to uniform distribution of the nanoparticles. However, further investigation using scanning electron microscope is required to confirm this result. Similar behavior has been reported elsewhere [23-24].

\section{Conclusion}

Polypropylene matrix reinforced by nanoplatelets of MMT has been expanded for different weight fractions of MMT platelets. The mechanical tests performed on specimens of the obtained nanocomposite showed a significant increase of the tensile modulus with less than $10 \mathrm{wt} \%$ fractions of reinforcement. The small 
dimensions and the shape of the platelet-like reinforcement are mostly responsible for this increment.The PP-MMT nanocomposites were prepared using melt-mixing and injection mouolding process. From the results, it could be concluded that PP-MMT nanocomposites are mechanically superior compared with the Neat PP. The tensile modulus, tensile strength, and notched Izod impact strength were improved by the addition of MMT by $24.3 \%, 11.25 \%$ and $23.95 \%$ respectively. Whereas, the \%elongation (strain) at break has reduced from $120 \%$ to $55 \%$ by the addition $8 \mathrm{wt} \%$ of MMT.

\section{Acknowledgement}

The work described in this paper is supported by the UNIIG fund for research under Innovation and Research Management Centre (iRMC) of Universiti Tenaga Nasional (UNITEN) (Project No. J510050686). Authors would like to thank Mr.Wouter, M/s CeTeau Sdn.Bhd. for his collaborative support.

\section{References}

[1] A. Arulrajah, H. Nikraz, and M. W. Bo, "Factors affecting field instrumentation assessment of marine clay treated with prefabricated vertical drains," Geotext. Geomembranes, vol. 22, no. 5, pp. 415-437, 2004.

[2] M. W. Bo, A. Arulrajah, S. Horpibulsuk, and M. Leong, "Quality management of prefabricated vertical drain materials in mega land reclamation projects: A case study," Soils Found., vol. 55, no. 4, pp 895-905, 2015.

[3] E. M. Da Silva, J. L. Justo, P. Durand, E. Justo, and M. VázquezBoza, "The effect of geotextile reinforcement and prefabricated vertical drains on the stability and settlement of embankments," Geotext. Geomembranes, vol. 45, no. 5, pp. 447-461, 2017.

[4] L. Li and R. K. Rowe, "Geosynthetic-reinforced embankments ove soft foundations," Geosynth. Int., vol. 12, no. 1, pp. 50-85, 2005.

[5] J. Chu, M. W. Bo, and V. Choa, "Practical considerations for using vertical drains in soil improvement projects," vol. 22, pp. 101-117, 2004.

[6] H. long Liu and J. Chu, "A new type of prefabricated vertical drain with improved properties," Geotext. Geomembranes, vol. 27, no. 2, pp. 152-155, 2009.

[7] M. Rezania, M. Bagheri, M. Mousavi Nezhad, and N Sivasithamparam, "Creep analysis of an earth embankment on soft soil deposit with and without PVD improvement," Geotext. Geomembranes, vol. 45, no. 5, pp. 537-547, 2017.

[8] B. Indraratna, T. T. Nguyen, J. Carter, and C. Rujikiatkamjorn, "Influence of biodegradable natural fibre drains on the radial consolidation of soft soil," Comput. Geotech., vol. 78, pp. 171-180, 2016.

[9] G. A. Lorenzo, D. T. Bergado, W. Bunthai, D. Hormdee, and P. Phothiraksanon, "Innovations and performances of PVD and dual function geosynthetic applications," Geotext. Geomembranes, vol. 22, no. 1-2, pp. 75-99, 2004.

[10] D. J. Lee, "Fracture mechanical model for tensile strength of particle reinforced elastomeric composites," Mech. Mater., vol. 102, pp. $54-60,2016$

[11] A. Dorigato, Y. Dzenis, and A. Pegoretti, "Filler aggregation as a reinforcement mechanism in polymer nanocomposites," Mech. Mater., vol. 61, pp. 79-90, 2013.

[12] M. K. Hassanzadeh-Aghdam, R. Ansari, M. J. Mahmoodi, and A. Darvizeh, "Effect of nanoparticle aggregation on the creep behavior of polymer nanocomposites," Compos. Sci. Technol., vol. 162, no. April, pp. 93-100, 2018.

[13] V. Cannillo et al., "Modeling of ceramic particles filled polymermatrix nanocomposites," Compos. Sci. Technol., vol. 66, no. 7-8, pp. 1030-1037, 2006.

[14] G. M. Odegard, T. C. Clancy, and T. S. Gates, "Modeling of the mechanical properties of nanoparticle/polymer composites," Polymer (Guildf)., vol. 46, no. 2, pp. 553-562, 2005.

[15] A. A. Edathil, P. Pal, and F. Banat, "Alginate clay hybrid composite adsorbents for the reclamation of industrial lean methyldiethanolamine solutions," Appl. Clay Sci., vol. 156, no. January, pp. 213-223, 2018

[16] Y. Yi, S. Liu, and A. J. Puppala, "Bearing capacity of composite foundation consisting of T-shaped soil-cement column and soft clay," Transp. Geotech., vol. 15, pp. 47-56, 2018.

[17] M. A. Islam, Y. L. Tan, M. A. Islam, M. Romi, and B. H. Hameed, "Chitosan - bleaching earth clay composite as an e ffi cient adsorbent for carbon dioxide adsorption: Process optimization," vol. 554, no. May, pp. 9-15, 2018.

[18] G. Lv et al., "Detection and quantification of phenol in liquid and gas phases using a clay/dye composite," J. Ind. Eng. Chem., vol. 62, pp. 284-290, 2018.

[19] O. A. Madyan, M. Fan, and Z. Huang, "Functional clay aerogel composites through hydrophobic modification and architecture of layered clays," Appl. Clay Sci., vol. 141, pp. 64-71, 2017.

[20] O. M. Istrate and B. Chen, "Structure and properties of clay/recycled plastic composites," Appl. Clay Sci., vol. 156, no. January, pp. 144-151, 2018.

[21] M. Raji, M. E. M. Mekhzoum, D. Rodrigue, A. el kacem Qaiss, and R. Bouhfid, "Effect of silane functionalization on properties of polypropylene/clay nanocomposites," Compos. Part B Eng., vol. 146, no. December 2017, pp. 106-115, 2018.

[22] C. I. W. Calcagno, C. M. Mariani, S. R. Teixeira, and R. S. Mauler, "The role of the MMT on the morphology and mechanical properties of the PP/PET blends," Compos. Sci. Technol., vol. 68 , no. 10-11, pp. 2193-2200, 2008.

[23] W. Xu, G. Liang, H. Zhai, S. Tang, G. Hang, and W. P. Pan, "Preparation and crystallization behaviour of PP/PP-g-MAH/OrgMMT nanocomposite," Eur. Polym. J., vol. 39, no. 7, pp. $1467-$ 1474, 2003.

[24] D. Shi, W. Yu, R. K. Y. Li, Z. Ke, and J. Yin, "An investigation on the dispersion of montmorillonite (MMT) primary particles in PP matrix," Eur. Polym. J., vol. 43, no. 8, pp. 3250-3257, 2007.

[25] T. Wu, D. Yuan, F. Qiu, R. Chen, G. Zhang, and J. Qu, "Polypropylene / polystyrene / clay blends prepared by an innovative eccentric rotor extruder based on continuous elongational fl ow: Analysis of morphology, rheology property, and crystallization behavior," Polym. Test., vol. 63, pp. 73-83, 2017.

[26] M. E.Elmashad and A.A.Ata, "Effect of seawater on consistency, infiltration rate and swelling characteristics of montmorillonite clay," HBRC J., vol. 12, no. 2, pp. 175-180, 2016.

[27] B. Tiwari and B. Ajmera, "Consolidation and swelling behavior of major clay minerals and their mixtures," Appl. Clay Sci., vol. 54, no. 3-4, pp. 264-273, 2011.

[28] M. Eldin M. A. Elmashad, "Improving the geotechnical behavior of sand through cohesive admixtures," Water Sci., vol. 32, no. 1, pp. $67-78,2018$.

[29] M.Manoraj and M.N.M.Ansari, "The effect of injection molding process paramters on impact strength of polypropylenehydroxyapatite biocomposite" J.Mechanical Engineering and Sciences, vol.11, No.2, pp.2581-2591, 2017.

[30] M.Manoraj, M.N.M.Ansari, R.A.Shanks, "Review on the effects of process parameters on strength, shrinkage and warpage of injection molding plastic component" Polymer-Plastics Technology and Engineering, vol.56,No.1, pp.1-12, 2017. 